\title{
SOIL EROSION ESTIMATION USING THE EPM MODEL
}

\author{
Efthimiou N. ${ }^{1}$ and Lykoudi E. ${ }^{2}$ \\ ${ }^{1}$ Agricultural University of Athens, Department of Natural resources Management and \\ Agricultural Engineering, Faculty of Water Resources Management, Iera Odos 75, 11855, Athens, \\ Greece,efthimiounik@yahoo.com \\ ${ }^{2}$ National Technical University of Athens, School of Mining and Metallurgical Engineering \\ Faculty of Geological Sciences, Heroon Polytechniou 9, 15780, Athens, Greece, \\ elykoudi@metal.ntua.gr
}

\begin{abstract}
The study aims to evaluate soil erosion and investigate its spatial distribution by applying the empirical EPM (i.e. Erosion Potential Model) at mountainous Mediterranean type catchments. Study area includes the catchments of Venetikos; Kalamas; Upper Acheloos and Arachthos Rivers (eight subcatchments in total), very important aquatic systems of NW Greece. The model was implemented both annually and inter-annually. A GIS-based approach was adopted, considering the spatial variation of its factors, as well as the erosion processes occurring in a catchment. The results were initially validated by being compared to the observed sediment yield values (based on the sediment discharge measurements conducted by the PPC). The model's performance was poor, significantly underestimating the results at both time scales. The ambiguous reliability of the PPC measurements led to their replacement by simulated ones, estimated using the sediment discharge rating curves methodology. Regarding the latter, the model performed better, attributing more accurate results, yet anew underestimated. However, it managed to identify the most susceptible to erosion areas. The poor performance is mainly attributed to its inherent shortcomings along with the specific characteristics and sedimentary regime of the study area.

Keywords: Gavrilovic, model, sediment yield, NW Greece.
\end{abstract}

\section{Пєрі́ $\eta \psi \eta$}

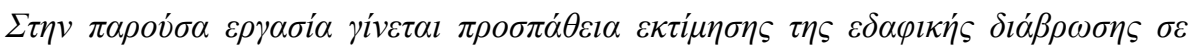

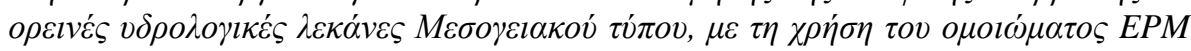

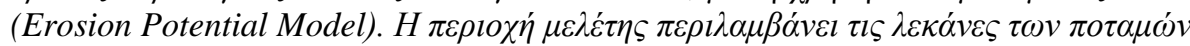

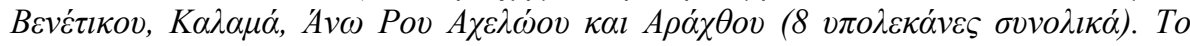

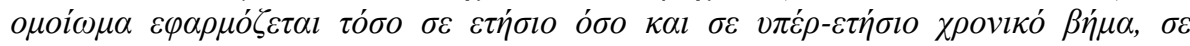

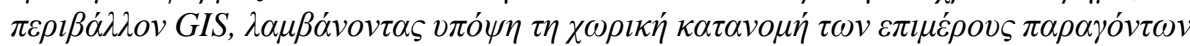

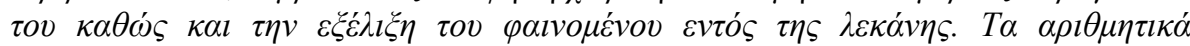

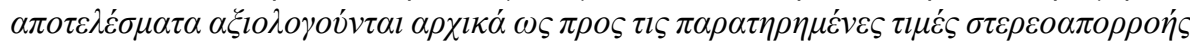
(

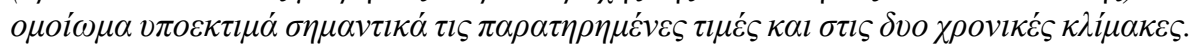

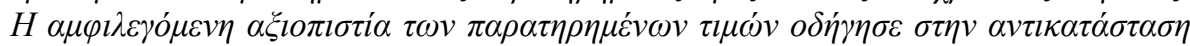

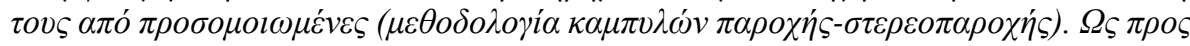

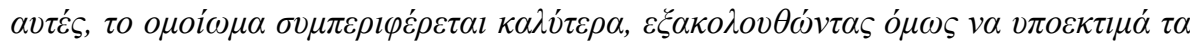

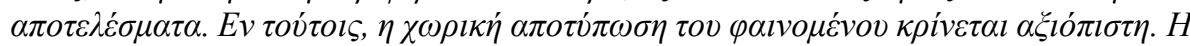




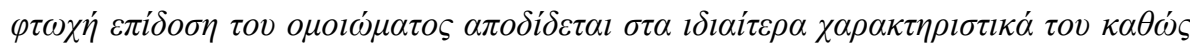

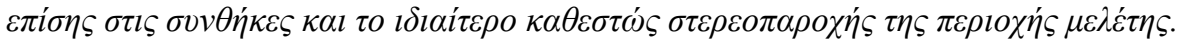

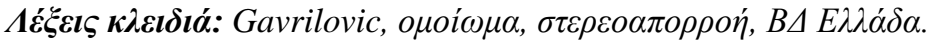

\section{Introduction}

Soil erosion, defined as the wearing away of the top soil layer, is the result of the combined rainfall impact and surface runoff effect, by means of detaching and subsequently transporting soil particles. It is a worldwide environmental problem that affects both the natural (e.g. soil degradation, water quality degradation, flooding risk) and the anthropogenic (e.g. reduction of reservoir capacity, agriculture productivity regression) environment. The phenomenon is controlled by natural factors such as soil properties, local topography, climate, vegetation cover, catchment morphology, drainage network characteristics and land use, as well as human activities (e.g. tillage, deforestation) that exacerbate its processes.

The assessment of soil erosion and sediment transport in hydrological catchments is imperative, in different temporal and spatial scales, in order to protect and preserve soil as long as technical constructions such as irrigation dams, hydroelectric projects and flood attenuation structures. This need has led to the development of different simulation models with varying accuracy and complexity (e.g. categorized into empirical, conceptual and physically based considering the different delineation of the phenomenon's complex detachment-transfer-deposition mechanism). Empirical models are widely applied, especially in countries where the availability of input data is often scarce and the validity ambiguous (such as Greece), because of their simplicity and ease of use, having less input data and computation demands than the comprehensive ones.

Considering the above, this study aimed to evaluate the performance of EPM at four mountainous Mediterranean type catchments of NW Greece (eight subcatchments in total), namely the Venetikos; Kalamas; Upper Acheloos and Arachthos Rivers catchments.

\section{Materials and Methods}

\subsection{Study area}

Study area includes four mountainous (mainly steep slopes and intense geomorphology; less mild slopes and minor lowlands) Mediterranean type (hot and dry summers followed by relatively mild winters with severe torrential rains) catchments of NW Greece (Fig. 1), namely the Venetikos River catchment, the Kalamas River catchment \{ separated into two consecutive sub-catchments, namely Soulopoulo Br. (i.e. Bridge) and Kioteki\}, the Arachthos River catchment (separated into four adjacent sub-catchments, namely Arta Br., Plaka Br., Tsimovo Br. and Gogo Br.) and the upper Acheloos River catchment (namely Avlaki Dam).
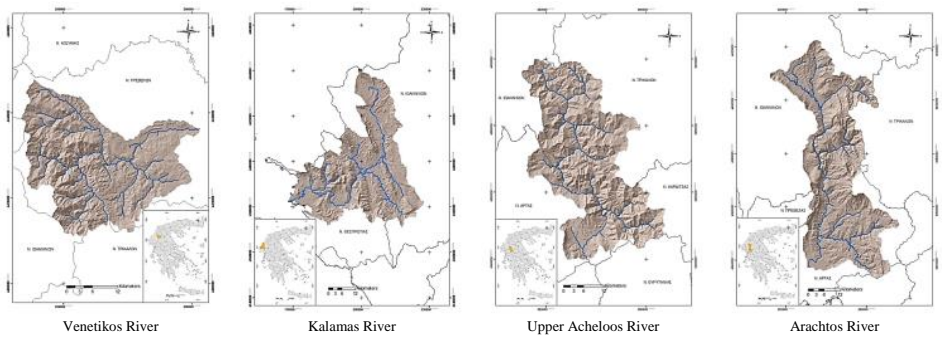

Figure 1 - Study area catchments.

The catchments are some of the most important aquatic systems of Greece. The availability of input data and sediment discharge measurements, provided the opportunity to implement the EPM and assess its performance at all basins, expanding and amplifying the conclusions. 


\subsection{Input data}

The catchments' topographic features (area, mean slope) were calculated based on the corresponding DEM's $\left(25 \mathrm{~m}^{2}\right.$ grid cell area, $25 \mathrm{~m}$ contour interval, scale 1:50.000).

Concerning the climatic attributes, daily temperature and precipitation measurements of the region's meteorological stations were considered. Since their values referred to the location and elevation of each station, they needed to be normalized to the corresponding catchments' total area and mean elevation. Regarding the temperature data, the methodology of Koytsoyiannis and Xantopoulos (1999) was adopted (one gauging station per catchment), according to Equation 1.

\section{Equation 1 - Annual volume of detached soil (W)}

$\mathrm{T}_{\mathrm{s}}=\mathrm{T}_{\sigma}-\alpha\left(\mathrm{z}_{\mathrm{s}}-\mathrm{z}_{\sigma}\right)$

where $\mathrm{T}_{\mathrm{s}}\left({ }^{\circ} \mathrm{C}\right)$ is the catchment's normalized mean temperature, $\mathrm{T}_{\sigma}\left({ }^{\circ} \mathrm{C}\right)$ is the station's mean temperature, $\alpha\left({ }^{\circ} \mathrm{C} / \mathrm{m}\right)$ is the temperature gradient, $\mathrm{z}_{\mathrm{s}}$ and $\mathrm{z}_{\sigma}$ are the catchment's mean elevation and station elevation, respectively.

The catchments' normalized mean annual precipitation was calculated by implementing the Thiessen interpolation method (surface reduction), using moreover the precipitation gradient (mean elevation correction).

The sediment discharge measurements - necessary for the cross-evaluation of the model's attributed results - have been conducted on a monthly basis by the Greek Public Power Corporation (PPC) at the outlet of each catchment, for the corresponding time periods.

Table 1 - Relative subcatchment attributes.

\begin{tabular}{|l|c|c|c|c|c|c|}
\hline Subcatchment & $\mathbf{F ~}\left(\mathbf{k m}^{\mathbf{2}}\right)$ & $\mathbf{J}(\boldsymbol{\%})$ & Period & $\mathbf{h}(\mathbf{m m})$ & $\mathbf{t}\left({ }^{\mathbf{o}} \mathbf{C}\right)$ & $\mathbf{Q}_{\mathbf{s}}(\mathbf{k g} / \mathbf{s})$ \\
\hline Grevena Br. & 855.23 & 23.64 & $1965-1982$ & $1,015.1$ & 9.6 & 1.79 \\
\hline Soulopoulo Br. & 671.45 & 14.50 & $1987-2002$ & $1,224.0$ & 14.4 & 2.29 \\
\hline Kioteki & $1,489.4$ & 15.00 & $»$ & $1,226.8$ & 11.4 & 7.39 \\
\hline Avlaki Dam & $1,354.92$ & 21.52 & $1965-1984$ & $1,696.0$ & 12.4 & 26.22 \\
\hline Arta Br. & $1,889.69$ & 14.38 & $1965-1976$ & $1,543.6$ & 12.0 & 94.06 \\
\hline Plaka Br. & $1,000.54$ & 16.11 & $»$ & $1,487.5$ & 11.0 & 36.61 \\
\hline Tsimovo Br. & 646.21 & 14.31 & $»$ & $1,386.3$ & 10.7 & 11.70 \\
\hline Gogo Br. & 204.75 & 21.01 & $»$ & $1,723.0$ & 7.9 & 4.69 \\
\hline
\end{tabular}

The Greek IGME (i.e. Institute of Geological and Mining Exploration) geological maps in a scale of 1:50.000 were used in order to initially group the individual geological formations into the final integrated ones (considering their geological age and lithological characteristics) and create the corresponding unified maps. Subsequently, the ranking within each group was based upon each formation's vulnerability to erosion and capability of sediment production (considering aspects such as water permeability and percolation). The formations were anew grouped into three major geological age groups (Quaternary, Neogene, Pre-Neogene), with the latter including the Paleogene, Cretaceous, Jurassic, Triassic, Paleozoic periods formations. Since all catchments are located at NW Greece (mainly within the external Hellenides geotectonic zones/ Pindos, Ionian), their geological formations are mostly comprised of sedimentary formations. In general, the formations met were limestones, hornstones, ophiolites (composed by volcano-sedimentary formations such as peridotites, gabbros, amphibolites, basalts etc.), flysch, clay schists, conglomerates, sandstones, marls, quaternary alluvial deposits (terraces, talus cones and scree etc.).

The land use-land cover map derived from the CORINE Land Cover 2000 database. 


\subsection{The Erosion Potential Model (EPM)}

The Erosion Potential Model (EPM) (Gavrilovic, S., 1962; 1970; 1972), also known as Gavrilovic method, is a widespread empirical model used for estimating sediment yield and soil erosion severity on catchment scale. The method considers six individual factors, depending on geology and soil properties, topographic features, climate, land use and degree of erosion. It has been widely implemented in several countries (Serbia, Croatia, Slovenia, Italy etc), with Greece being one of them (Efthimiou et al., 2016; Emmanouloudis et al., 2003; Stefandis et al., 1998), providing reliable results.

The annual volume of detached soil due to surface erosion is calculated by Equation 2 .

\section{Equation 2 - Annual volume of detached soil (W)}

$\mathrm{W}=\mathrm{T} \cdot \mathrm{h} \cdot \pi \cdot \sqrt{\mathrm{z}^{3}} \cdot \mathrm{F}$

where $\mathrm{W}$ is the average annual erosion $\left(\mathrm{m}^{3} / \mathrm{y}\right)$, $\mathrm{T}$ is the temperature coefficient, $\mathrm{h}$ is the mean annual rainfall $(\mathrm{mm}), \mathrm{F}$ is the catchment area $\left(\mathrm{Km}^{2}\right)$, and $\mathrm{z}$ is the erosion coefficient. The latter, according to Staut (2004) is the measure of intensity or density of erosion processes. Its values are tabulated, ranging from 0.19 or less (lower limit of the "Very slight" class) to 1.0 or more (upper limit of the "Severe" class).

The temperature coefficient $(\mathrm{T})$ is calculated by Equation 3.

\section{Equation 3 - Temperature coefficient $(T)$}

$$
\mathrm{T}=\sqrt{(\mathrm{t} / 10)+0.1}
$$

where $\mathrm{t}$ is the mean annual temperature $\left({ }^{\circ} \mathrm{C}\right)$.

The erosion coefficient ( $\mathrm{z}$ ) is calculated by Equation 4 .

\section{Equation 4 - Erosion coefficient (z)}

$$
\mathrm{z}=\mathrm{x} \cdot \mathrm{y} \cdot(\varphi+\sqrt{\mathrm{J}})
$$

where $\mathrm{x}$ is the soil protection coefficient, $\mathrm{y}$ is the soil erodibility coefficient, $\varphi$ is the erosion and stream network development coefficient and $\mathrm{J}$ is the mean slope of the catchment (\%).

Soil protection coefficient $(\mathrm{x})$ (depends on land use and vegetation cover) expresses numerically the protection of an area against precipitation and erosion. It consists of two independent coefficients, namely the land use coefficient (x) (depends on land category, characteristics of vegetation association and degree of vegetation cover) and the vegetation cover coefficient (a) (depends on the measures taken to reduce erosion activities, mainly in agriculture), treated as one. Its values are tabulated, ranging from 0.05 (lower limit of the "Mixed and dense forest" class) to 1.0 (upper limit of the "Areas without vegetal cover" class).

Soil erodibility coefficient (y) (depends on geology) can be expressed as the inverse value of the resistance of soil to erosion due to the erosive force of precipitation. Its values are tabulated, ranging from 0.20 (lower limit of the "Hard rock, erosion resistant" class) to 2.0 (upper limit of the "Fine sediments and soils without erosion resistance" class).

Coefficient $\varphi$ stands for the degree of expressed erosion processes (visibly characterized) in the catchment. Its values are tabulated, ranging from 0.10 (lower limit of the "Limited erosion on watershed" class) to 1.0 (upper limit of the "Whole watershed affected by erosion" class). 


\subsection{Model implementation}

Considering the spatial distribution of the input data as well as the erosion phenomenon's progress in a catchment, the model was implemented in a GIS-based environment, leading to a more accurate result. At such delineation, each factor is described by the form of a digital map. The digital layers are overlaid in order to estimate soil loss in the watershed.

The temperature coefficient $(\mathrm{T})$ is estimated concerning the catchments' normalized mean annual temperature.

Considering the CORINE Land Cover 2000 classification, a value of the $\mathrm{x}$ coefficient was assigned to every coded land use met in the catchment. The lowest values occur at areas of high vegetation cover denoting the protective effect of the latter against soil erosion, while the highest at areas of mild or low vegetation cover (Fig. 2).

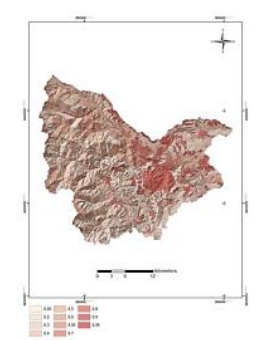

Grevena Br.

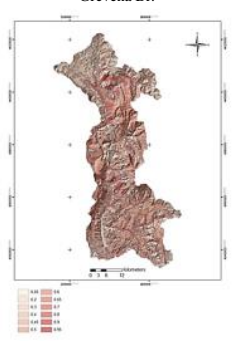

Arta Br.

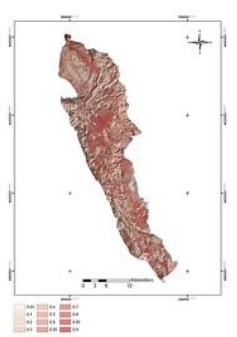

Soulopoulo Br.

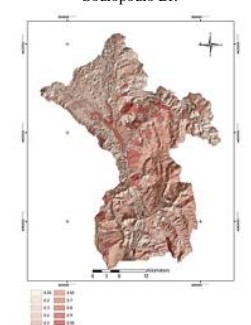

Plaka Br.

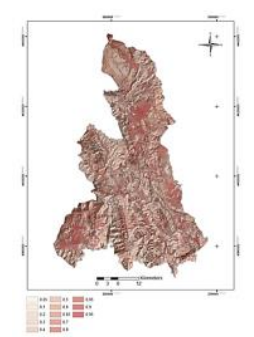

Kioteki

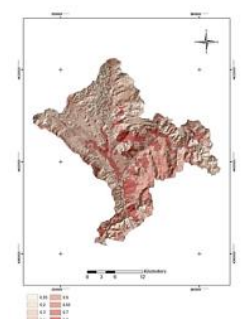

Tsimovo Br.
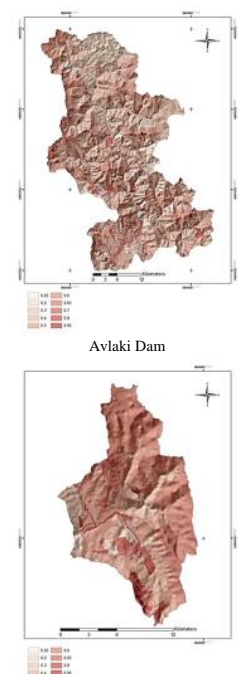

Gogo Br.

Figure 2 - Soil protection coefficient (x).

The integration methodology of the geological formations followed is not suitable for drawing conclusions concerning their torrential properties. To that end, they were anew grouped into six major categories \{namely Chalky (K), Flysch (F), Schistose (G), Crystalline-igneous (M), Neogene (S) and Alluvial (A)\}, considering the Kotoulas (1972) theory on torrential petrographic formations (Fig. 3). According to which, a catchment's torrential environment is determined by the combination of three basic torrential factors (climate, relief and geology), attributing torrential phenomena of different type, form, extent and intensity. 

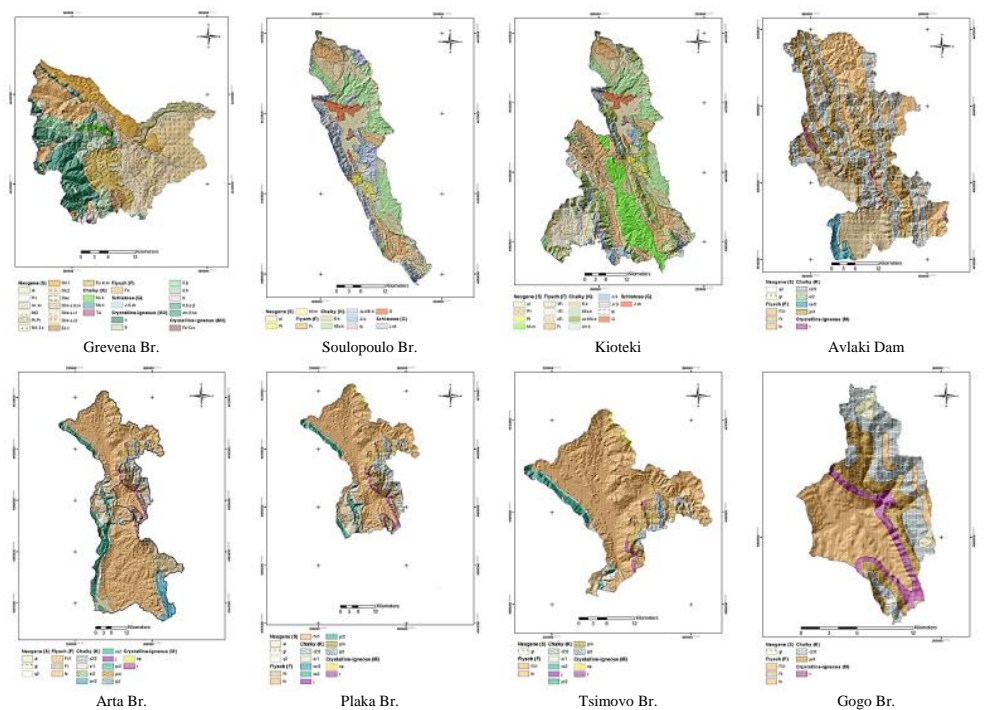

Figure 3 - Integrated Geological Formations (Torrential attributes classification).

A y coefficient value was then assigned to every coded geological formation met in each catchment. The highest values occur at areas close to the catchments' outlet, relatively moderate values at their lowlands, while the lowest values at areas of high relief (Fig. 4).

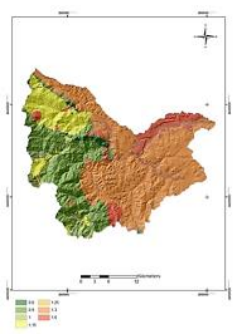

Grevena Br.

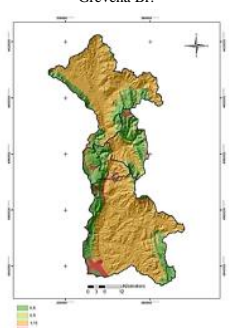

Arta Br.

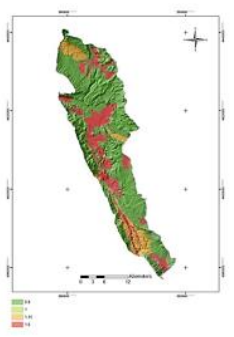

Soulopoulo Br

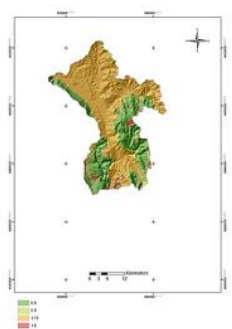

Plaka Br.

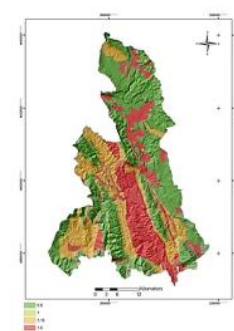

Kioteki

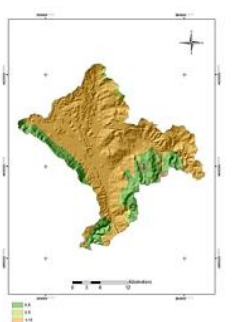

Tsimovo Br.

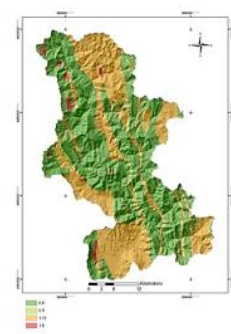

Avlaki Dam

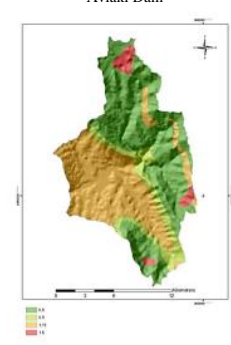

Gogo Br.

Figure 4 - Soil erodibility coefficient (y).

Mean slope (Table 1) was assessed considering each catchment's corresponding DEM. The highest values occur at areas of high relief and the lowest at the lowlands, with the latter gradually declining towards their outlets.

The $\varphi$ coefficient values were determined after field observation.

Considering the $\mathrm{x} ; \mathrm{y} ; \varphi ; \mathrm{J}$ factors, $\mathrm{z}$ coefficient is calculated and classified. The highest values are met at the catchments' lowlands, due to the corresponding high values of the $\mathrm{x}, \mathrm{y}$ factors occurring at these areas (Fig. 5). Slope does not affect the result to the specific areas as much (low values, degraded by being involved in Eq. 3 as its square root). 

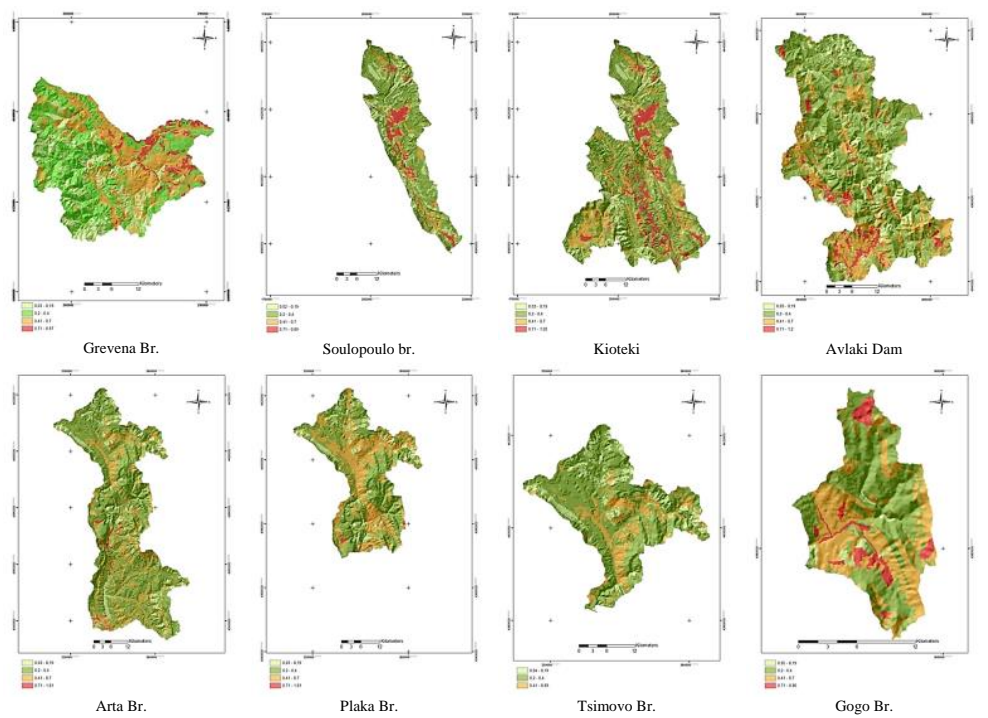

Figure 5 - Erosion coefficient (z).

\section{Results}

Concerning the inter-annual implementation of the EPM, mean annual (compact) volume of detached soil due to surface erosion $\left(\mathrm{W}, \mathrm{m}^{3} / \mathrm{y}\right.$ ) was initially calculated. The result was multiplied to the soil's specific weight value (usually equal to $2.67 \mathrm{t} / \mathrm{m}^{3}$, ranging between $2.65 \sim 2.75 \mathrm{t} / \mathrm{m}^{3}$ ) in order to be expressed in the same units as the PPC measurements, and thus allow the comparison between them. Mean annual soil loss estimated (W, t/y), corresponds to mean annual soil loss per unit area (Fig. 6) $\left\{\right.$ mean annual gross erosion - also referred as mean annual specific erosion $\left.\left(\mathrm{W}_{\mathrm{sp}}, \mathrm{t} / \mathrm{km}^{2} / \mathrm{y}\right)\right\}$ considering the area (Table 1) of each catchment.
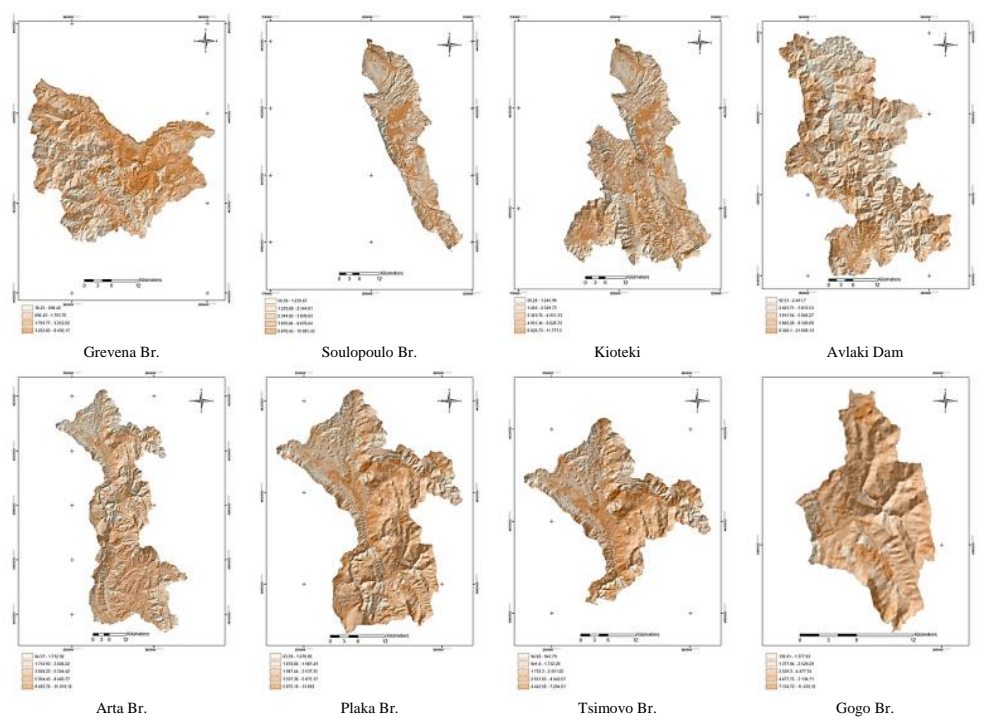

Figure 6 - Soil loss per unit area $\left(\mathrm{t} / \mathrm{Km}^{2} / \mathrm{y}\right)$.

Only a fraction of the total sediment volume produced within a catchment results to its outlet, since a large portion is deposited during its course towards the water bodies. The effective sediment transported to the catchment's outlet (routing is not taken into account) \{ actual sediment yield (G, 
$\left.\left.\mathrm{m}^{3} / \mathrm{y}\right)\right\}$ is determined by the SDR (i.e. Sediment Delivery Coefficient), estimated using the Renfro (1972) methodology. SDR was applied to the mean annual soil loss per unit area, resulting to transported gross erosion \{or SY (i.e. Sediment Yield) \} at the catchments' outlets (Table 2).

Table 2 - Inter-annual sediment yield results.

\begin{tabular}{|l|c|c|c|c|c|}
\hline Subcatchment & $\mathbf{W}_{\text {sp }}\left(\mathbf{t} / \mathbf{K m}^{2} / \mathbf{y}\right)$ & SDR & SY $\left(\mathbf{t} / \mathbf{k m}^{2} / \mathbf{y}\right)$ & $\mathbf{P P C}\left(\mathbf{t} / \mathbf{K m}^{\mathbf{2}} / \mathbf{y}\right)$ & $\mathbf{Q - Q} \mathbf{\text { s }}\left(\mathbf{t} / \mathbf{K m}^{\mathbf{2}} / \mathbf{y}\right)$ \\
\hline Grevena Br. & $2,145.97$ & 0.23 & 491.64 & 791.99 & 548,89 \\
\hline Soulopoulo Br. & $2,997.16$ & 0.21 & 632.40 & 1.878 .02 & 1.878 .02 \\
\hline Kioteki & $2,907.24$ & 0.24 & 689.89 & 1.291 .61 & 1.291 .61 \\
\hline Avlaki Dam & $3,852.14$ & 0.21 & 823.20 & 7.322 .46 & $4,964.21$ \\
\hline Arta Br. & $3,417.62$ & 0.20 & 696.17 & 18.837 .03 & $9.341,48$ \\
\hline Plaka Br. & $3,000.46$ & 0.22 & 671.50 & 13.847 .11 & $8.779,05$ \\
\hline Tsimovo Br. & $2,572.96$ & 0.24 & 614.17 & 6.851 .84 & $2.886,27$ \\
\hline Gogo Br. & $4,015.23$ & 0.28 & $1,135.91$ & 8.675 .16 & $6.828,67$ \\
\hline
\end{tabular}

It is noted that the observed SY values at Soulopoulo Br. and Kioteki basins are not calculated based on sediment discharge measurements but estimated by using the "broken line interpolation" sediment discharge rating curve method.

The final results are significantly lower than the initial estimates, yet considerably underestimated (apart from the Grevena Br. subcatchment) compared to the observed (measured) PPC values of mean annual sediment yield.

The model is also implemented annually, following the same procedure. The (low annual) fluctuation of the simulated values is attributed to the corresponding fluctuation of mean annual temperature and precipitation, since all other factors remain unchanged. The results are also underestimated throughout the whole time period. Moreover, the model's inconsistent behavior is attributed to the low variation of mean annual temperature and precipitation, as well as the corresponding high variation of the measured sediment yield and discharge values.
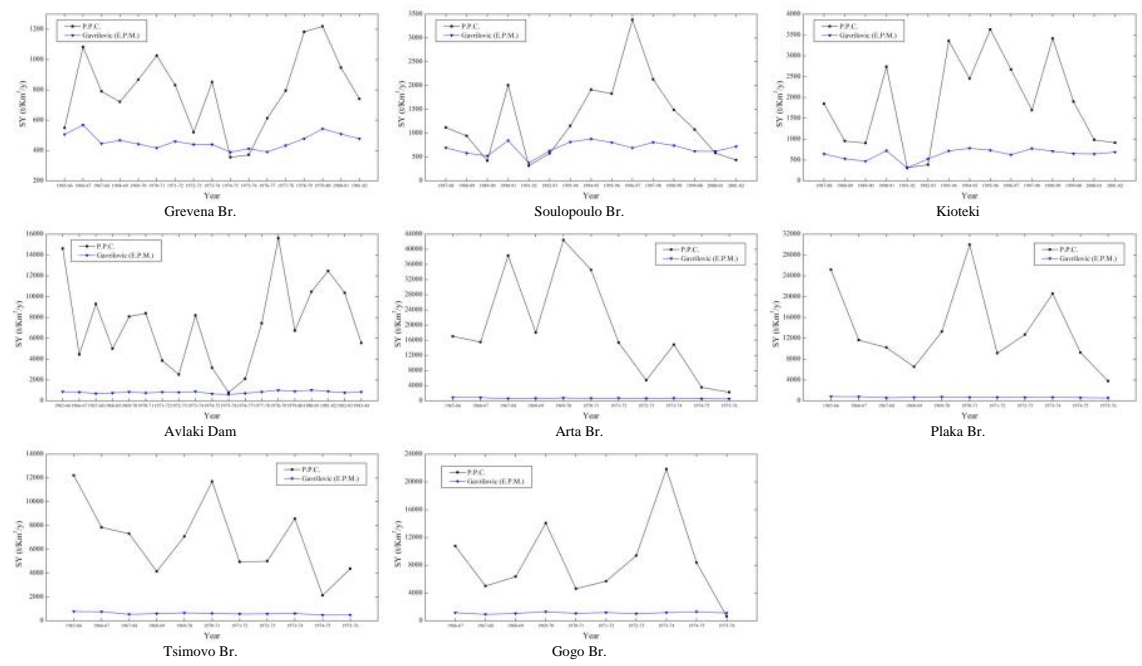

Soulopoulo B
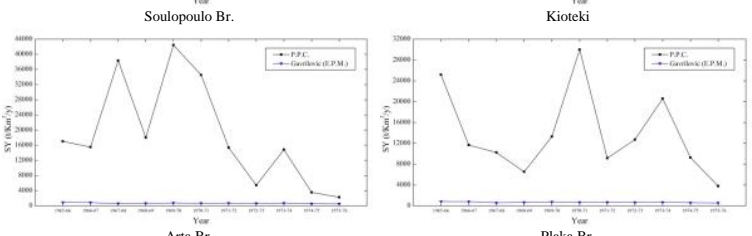

Arta B

Plaka Br.

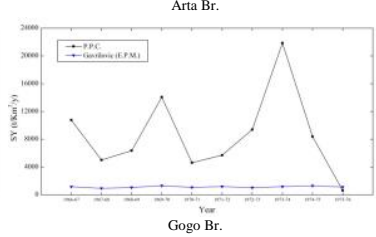

Figure 7 - Annual sediment yield (t/ $\left.\mathrm{Km}^{2} / \mathrm{y}\right)$ against PPC measurements.

The underestimation is primarily attributed to the ambiguous reliability of the sediment discharge measurements (infrequent and often inadequate, having a random and unsystematic character, concerning only the suspension load etc.). Overall, the specific measurements are considered significantly overestimated \{e.g. at Arachtos' subcatchments, high erosion rates could be justified due to the extensive presence of flysch (notably prone to water erosion), combined with intense 
topography and erosive precipitation - yet the measured values although expected high, are considered unrealistic\}.

Moreover, is attributed to the model's inherent shortcomings and limitations. The equation was developed using statistical techniques (regression analysis), based on field data of small land sites with relatively similar characteristics. Thus, its application on catchment scale (where non-uniform conditions occur) is questionable. Additionally, it has ambiguous applicability outside the range of conditions for which its coefficients were calculated, thus requiring recalibration to regions outside the original dataset. Furthermore, it describes the complex soil erosion mechanism by merely multiplying completely different factors, when in fact it cannot be simulated in such a simplified way (important aspects of the phenomenon such as sediment deposition and sediment routing are not taken into account). Also, the catchment's soil properties are described through its lithology, while characteristics like organic matter content and granulometry are discarded. Finally, the model estimates mean annual erosion, while having very low accuracy on individual flooding events, where most of the sediment load is transported, especially at Mediterranean catchments.

The catchments' specific characteristics \{mainly mountainous yet with several topographic variations, extensive vegetation cover at their mountainous regions (protective effect against soil erosion where the steep slopes occur/ counter action effect), temperature and erosive precipitation's spatial distribution, bed rock properties \} along with their different combinations patterns, also play a decisive role to the underestimation of the measured results.

It is noted that the model performs better at Venetikos River catchment, a fact attributed to its specific properties (relatively low precipitation erosivity, bed rock not prone to erosion, rainfallgeology-topography-land cover pattern combinations that do not allow high erosion rates, low sediment discharge/ yield values).

The ambiguous reliability of sediment discharge measurements (infrequent and often inadequate, having a random and unsystematic character, concerning only the suspension load), along with their lack at the Kioteki and Soulopoulo Br. subcatchments, led to their replacement by simulated ones, estimated based on the sediment discharge rating curves methodology (Fig. 8, Table 2). At each subcatchment, a representative rating curve construction method was chosen \{Grevena Br./ Soulopoulo Br./ Kioteki/ Avlaki Dam: Broken line interpolation, Arta Br./ Plaka Br./ Gogo Br.: Linear regression of the log-transformed variables (Ferguson correction), Tsimovo Br.: different ratings for the dry-wet season of the year \}, considering a statistical analysis.

The sediment yield simulated values are notably lower than the corresponding measured ones. Regarding the latter, the model performed better, attributing more accurate results, yet anew underestimated.

The model, while underestimating the numeric results, allowed identification of the most susceptible areas to water erosion.

Overall, we can conclude that despite its shortcomings, the method can provide a good basis in terms of a preliminary approximation. 

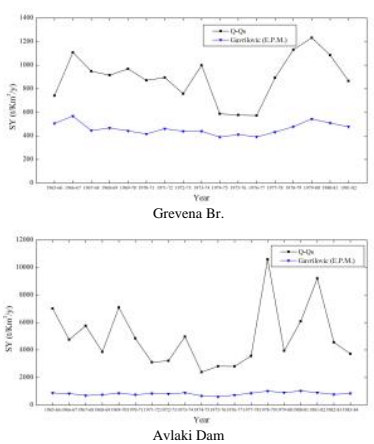

Avlaki D
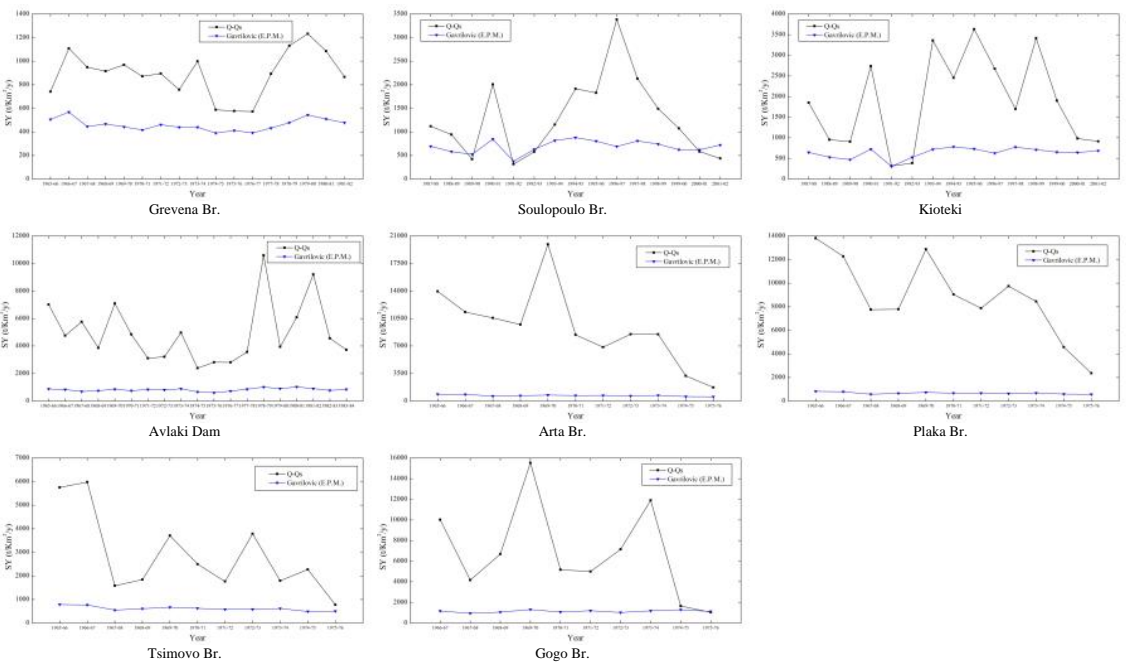

Figure 8 - Annual sediment yield (t/ $\left.\mathrm{Km}^{2} / \mathbf{y}\right)$ against Q-Qs estimations.

\section{References}

Efthimiou, N., Lykoudi, E., Panagoulia, D. and Karavitis, C., 2016. Assessment of soil susceptibility to erosion using the EPM and RUSLE models: the case of Venetikos River catchment, Global NEST Journal, 18(1), 164-179.

Emmanouloudis, D., Christou, O. and Filippidis, E., 2003. Quantitative estimation of degradation in the Aliakmon river basin using GIS. Erosion Prediction in Ungauged Basins: Integrating Methods and Techniques, IAHS Publication, 279, 234.

Gavrilovic, S., 1962. A method for estimating the average annual quantity of sediments according to the potency of erosion, Faculty of Forestry, 26, 151-168 (In Serbian).

Gavrilovic, S., 1970. Modern ways of calculating the torrential sediment and erosion mapping. In: Erosion, Torrents and Alluvial Deposits, Yugoslav Committee for International Hydrological decade, Belgrade, 85-100 (In Serbian).

Gavrilovic, S., 1972. Engineering of Torrents and Erosion, Belgrade, 292 pp. (In Serbian).

Kotoulas, D., 1972. The torrents of Southern Germany and Greece. Part. 1, Report No. 25, Munich, 1-177 (In German).

Koutsoyiannis, D. and Xanthopoulos, Th., 1999. Engineering Hydrology, Edition 3, 418 pages, National Technical University of Athens, Athens (In Greek).

Renfro, G.W., 1972. Use of erosion equations and sediment delivery ratios for predicting sediment yield. In: Sediment yield workshop: Present and prospective technology for predicting sediment yield and sources Proceedings, USDA Sedim. Labor. Oxford, Mass. USA, 33-45.

Staut, M., 2004. Recent erosional processes in the catchment of the Dragonja river, Unpublished graduate thesis. Faculty of Arts, University of Ljubljana, Ljubljana (In Serbian).

Stefanidis, P., Myronidis, D., Sapountzis, M. and Stathis, D., 1998. The torrent "Sklitrho" in Florina. Torrential Environment and torrent control system, Scientific Annals. Department of forestry and natural environment. Aristotelian University of Thessaloniki. 41(2), 1275. 